\title{
Optimization of Multimodal Transportation Network Based on Improved Genetic Algorithm
}

\author{
Yanlin Zhao* \\ Panzhihua University, Panzhihua City, Sichuan Province, China \\ ${ }^{*}$ Corresponding author
}

\begin{abstract}
Mathematical models of multimodal transportation are built by integrating transportation cost, conversion cost and punishment cost of time based the comparison of various modes of transportation. Model solutionalgorithm uses improved Genetic Algorithm added immigration factor, which can avoid the local optimum, ensure the diversity population, and enhance search abilities. Modelsare solved with MATLAB computing platform, and whichwillachievethe optimal network operation scheme of models. Example results show that portlogistics multimodal transportation network operation cost is reduced by $45.8 \%$,so this paper is verified the effectiveness and practicability of the proposed network operation models.
\end{abstract}

Keywords-multimodal transportation; genetic algorithm; network optimization

\section{INTRODUCTION}

During the 1920s, when the multi-modal transport between the United States and the railway transportation made the initial progress, it did not arouse the attention of the academic circles until the 1980s, which was gradually taken seriously by enterprises, governments and scholars. From that time to the present, the study of multimodal transport is still not systematic. In foreign countries, the study of multimodal transport mainly focuses on the combined transport. And the study is mainly based on details of multimodal transport, with few studies on the whole system of multimodal transport. Bontekoning Y M is the research object of the common rail transport system, and analyzes the influence factors of the interchange between the highway transportation system and the railway transportation system. As for the Dennis Rondinelli, from the perspective of the global economy to demonstrates the important position of multimodal transport in logistics. Lozano Aresearched the most short-circuit solutions for multimodal transport and considered multiple modes of transport for multimodal transport and complex networks for multiple transport nodes, and then the shortest path was found with the tag algorithm. Cooperation between Bas Groothedde through the enterprise builds a multimodal transport hub of the network to achieve the purpose of reduce logistics cost and maintenance cost. Then in hub with a lot of goods accumulated route enjoy a discount and can use the mode of transportation of transport costs low to meet the requirements of low cost.. By building a mathematical model of the collaborative hub is verified the practicability and reliability of the network.
When domestic scholars to study in the research of multimodal transport problems, then mainly can be divided into two large level of management and technology, the management research mainly focused on the development strategy, according to the laws and regulations as well as some coordination problem in the process of transportation, but technology research mainly focused on the path optimization, information sharing, and introduces some advanced electronic equipment, etc. For example,Yang Yuntao studied, the legal relationship of international multimodal transport of goods, and also analyzes the freight side of multimodal transport, the legal relationship between the operator andthe contract party, detailed research, and then he made the multimodal transport work. For example, Weihang has studied the shortest path algorithm for the transport time, cost and risk factors of multimodal transport with the change of time.

\section{BASIC PARAMETERS AND VARIABLES}

The model symbols are expressed as follows:

$N$ :node city set;

$M$ :modes of transport set;

$i 、 j$ :specific point city;

$m$ :specific transportation methods;

$d_{i j}$ :transportation distance from node i to node $\mathrm{j}$;

$C_{i j}^{m}:$ Unit cost of node i to node $\mathrm{j}$ which is using m mode of transport;

$W_{i j}:$ The volume from node i to node $\mathrm{j}$;

$t_{i j}$ :The actual total time from node i to node $\mathrm{j}$;

$t_{i j}^{m}$ :the time from node $\mathrm{i}$ to node $\mathrm{j}$ which is used the $\mathrm{m}$ method of transportation;

$I t_{i j}$ :Thelower limit time ofnode i to node j;

$u t_{i j}$ :The upperlimit time of node i to node $\mathrm{j}$;

$g$ :Penalty factor of the actual time below the lower limit time;

$f$ :Penalty factor of the actual time above the upper limit time; 
$M C_{m_{1} m_{2}}$ :the transfer cost of transferring transport mode $m_{1}$ to transport mode $m_{2}$, and so on; $L M_{m_{1} m_{2}}$ :the unit replacement cost of transferring transport
mode ${ }^{m_{1}}$ to transport mode ${ }^{m_{2}}$,and so on;

$L C$ :Unitloading and unloading cost

$L T$ :Unit loading and unloadingtime;

\section{MATHEMATICAL MODEL CONSTRUCTION}

\section{A. Problem Description}

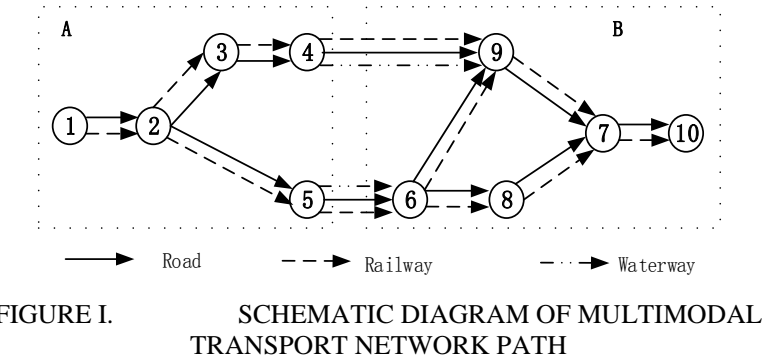

Figure 1, showing the schematic diagram of multimodal transportationwhich is fromthe Node city 1 of port hinterland A to the Node city 10 of port hinterland $B$, among them, the mode of transportation between two nodes is greater than or equal to two types. In the process of looking for the shortest path between node 1and node10. It not only needs to find out the nodes cities, but also choose thetransportation mode between every two nodes. The choice of node will affect the choice of transportation modebecause of the different way of transportation between nodes,and the choice of transportation modealso gives feedback to the excellent state after the node chooses through the cost or the time. Because of multitudinous logistics nodesand numerous transportation modes, the problem of multimodal transport network is a very special and complex shortest path problem.

\section{B. $\quad$ Model Building}

$$
\begin{gathered}
\sum_{i \in N} \sum_{j \in N} \sum_{l \in \Omega_{4}} \sum_{m \in \Omega_{m}} W_{i j}\left(C_{i j}^{m l} d_{i j}^{m l}+M C_{i j}^{m l}\right) X_{i j}^{m l}+\sum_{i \in N} \sum_{j \in N}\left(g\left(t_{i j}\right)+f\left(t_{i j}\right)\right) X_{i j}^{m l} \\
M C_{i j}^{m l}=L M_{i j}^{m l}+L C_{i j}^{m l} \\
g\left(t_{i j}\right)= \begin{cases}\left(l t_{i j}-t_{i j}\right) g & t_{i j}<l t_{i j} \\
0 & t_{i j} \geq l t_{i j}\end{cases} \\
f\left(t_{i j}\right)= \begin{cases}0 & t_{i j}<u t \\
\left(t_{i j}-u t\right) f & t_{i j} \geq u t\end{cases}
\end{gathered}
$$

$$
t_{i j}=\sum_{i \in N} \sum_{j \in N} \sum_{l \in \Omega_{1}} \sum_{m \in \Omega_{m}}\left(t_{i j}^{m l}+W_{i j} L T_{i j}^{m l}\right) X_{i j}^{m l}
$$

$$
\sum_{m \in \Omega_{m}} X_{i j}^{m l}=1
$$

$$
i \neq j
$$

$$
X_{i j}^{m l}= \begin{cases}1 & \text { Node } i \text { to node } j \text { adopts m operation mode } \\ 0 & \text { Other }\end{cases}
$$

Formula (1) is the objective function which mainly contains two parts. The first part is the total cost of transportation, and it includes the cost of transportation, changing the mold and loading and unloading. The second part is the time penalty function. Formula (2) is the sum of unit change cost and unit handing cost. Formula (3) and formula (4) respectively represent the lower limit and upper limit penalty function of the time that the total transportation time exceeding time constraint. Formula (5) represents the calculation of total actual transportation time, the first part represents the transport time,the second part represents loading and unloading time. Formula (6) indicates that only one mode of transportation can be selected between each two nodes.

\section{MOdel Algorithm Design}

\section{A. Design Encoding and Population Initialization}

In the network, 1,2,3 and such digital symbolsrepresent $n$ node cities, 1, 2 and 3 respectively represent the three modes of transportation of roads, railways and waterways. Chromosomes were divided into two segments code, the first sectionexpresses the number of path passing through the node cities,the second sectionexpresses the mode of transportation. It needs to insert the mode of transportation thatin second section into the gap of the first stage whiledoing intersecting, mutation, and other operation.See figure 2.

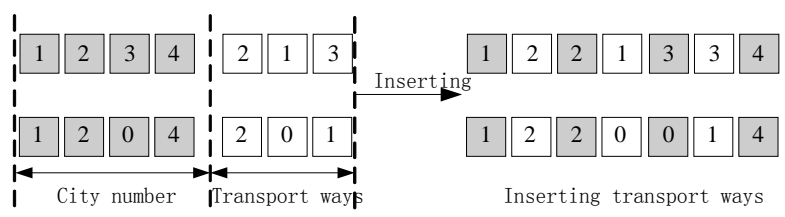

FIGURE II. CHROMOSOME CODING

The gray position of the chromosome represents the urban node passing through, and the white position indicates the mode of transportation between the node cities; when the node is not passed, it is expressed in 0 , and the corresponding mode of transportation is 0 too. The population initialization is using the method of random generation.

\section{B. Fitness Function Design}

The fitness function (fit) uses the inverse of the value of the objective function. Because the genetic algorithm is the 
one that keeps the maximum fitness valueindividual, however, because of the objective function of the solutionis the minimum value, we use the c of the objective function as the fitness function.

\section{Selection Operator Design}

Select function (select) adopts the combination way of elite individual retention and tournament selection. In the population size of $\mathrm{g}$ individuals, two individuals are randomly selected for comparison, the individuals with large fitness are retained in the next generation population and select $\mathrm{c}$ individuals by tournament selection; the remaining gcindividuals adopt elite retention strategies, and theg-c individuals with the largest fitness are remained in the next generation.

\section{Crossover Operator Design}

Cross function (cross) uses a two-point crossover criterion. Firstly, the population is randomly two-two pairing, secondly,at two intersection pointsrandomly,exchange the genes which are between the intersections of the twochromosomes and the new individual is obtained.

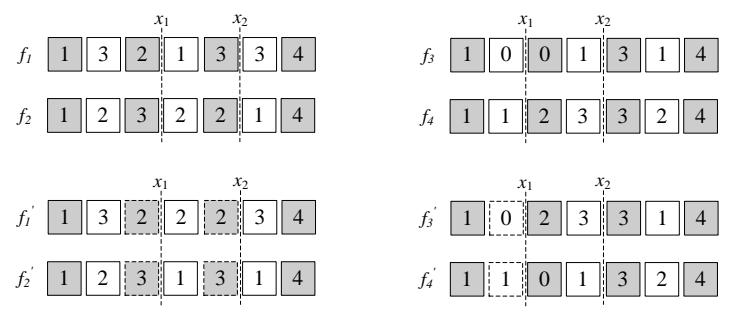

FIGURE III. SINGLE POINT CROSSOVER OPERATOR

As shown in Figure 3, $\mathrm{x} 1$ and $\mathrm{x} 2$ are randomly selected as intersections in the parent chromosome, thenexchange of genes between chromosomal intersections of the parent, and the two individual chromosomes of the new generation are obtained. It can be found by figure 3 that there are two 2 and two 33 in $\mathrm{f} 1$ 'and $\mathrm{f} 2$ and mismatched modes of transportation in $\mathrm{f} 3$ 'and $\mathrm{f} 4$ ', as shown in Figure 3 on the dotted line, therefore, it is necessary to check and correct the new chromosome after crossing. Repeat node testing and correction are performed first, and the nodes in the original chromosome need to be exchanged; then carry out the transportation mode matching inspection and correction.

\section{E. Mutation Operator Design}

The variation function (matam) adopts the reverse mutation strategy. The variation pattern is shown as figure 4 :

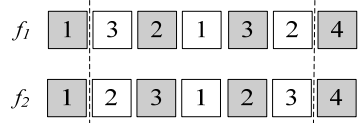

FIGURE IV.

INVERSE MUTATION OPERATOR

In the same way, the mutant chromosome also needs to be tested and corrected to determine whether the mode of transportation matches the node, and modify the chromosomes.

\section{F. Immigrant Operator Design}

Adda new group of individuals to the population to replace the old ones in the populationwhen the iterative algebra is an integer multiple of 10 , so as to ensure the diversity of the population, expand the search space of the algorithm, andprevent the obtaining of the local optimal solution. Introduced new individuals are generated by random generation.

The detailed flow design of genetic algorithm for multimodal transport network model is shown in figure 5 .

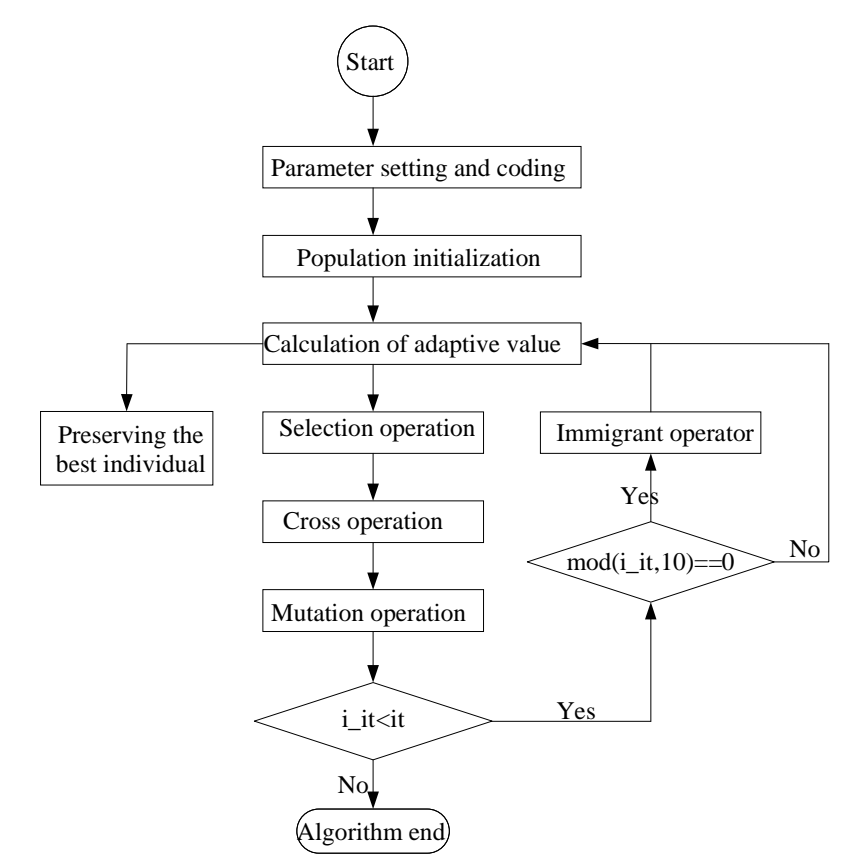

FIGURE V.

THE SPECIFIC PROCESS DESIGN OF GENETIC ALGORITHM

\section{CASE Analysis}

A seaport logistics limited company mainly carries on the port logistics service the third party logistics enterprise, which is established inHaiyan County, Hangzhou Bay, Zhejiang.

\section{A. Data Base}

- Node data.

The hinterland nodes of the Yangtze River Delta are composed of Nanjing, Nantong, Suzhou, Shanghai, Hangzhou, Jiaxing, Ningbo, Jinhua and Wenzhou, The nodes in the hinterland of the Pearl River Delta are composed of Shantou, Shanwei, Shaoguan, Qingyuan, Huizhou, Shenzhen, Guangzhou, Wuzhou, Yangjiang and Maoming, they are numbered in sequence number $C_{1} 、 C_{2} 、 C_{3} 、 C_{4} 、 C_{5} 、 C_{6}$ 、 $\mathrm{C}_{7} 、 \mathrm{C}_{9} 、 \mathrm{C}_{10} 、 \mathrm{C}_{11} 、 \mathrm{C}_{12} 、 \mathrm{C}_{13} 、 \mathrm{C}_{14} 、 \mathrm{C}_{15} 、 \mathrm{C}_{16} 、 \mathrm{C}_{17}, \mathrm{C}_{18} 、$ $\mathrm{C}_{19}$.

- Mileage data. 
Because of the space limitation, Road history, sea miles and railway mileage can be used to check the atlas of China's highway network, China railway atlas and Netpas Distance 3.1.

- Traffic data.

The network yearsis planned tobe 5 years, through a comprehensive consideration of multiple factors, the traffic volume between nodal cities in Yangtze River Delta and Pearl River Delta citiesthat are forecasted by enterprisecan be shown in table 4 (The unlisted flow is 0 ).

TABLE I. VOLUME OF FREIGHT BETWEEN SOME NODES (UNIT: TON)

\begin{tabular}{|c|c|c|c|c|c|c|}
\hline $\mathrm{N}$ & $\mathrm{C}_{1}-\mathrm{C}_{14}$ & $\mathrm{C}_{2}-\mathrm{C}_{18}$ & $\mathrm{C}_{3}-\mathrm{C}_{10}$ & $\mathrm{C}_{3}-\mathrm{C}_{11}$ & $\mathrm{C}_{3}-\mathrm{C}_{12}$ & $\mathrm{C}_{4}-\mathrm{C}_{12}$ \\
\hline weight & 3731 & 2589 & 2015 & 2123 & 2736 & 4729 \\
\hline $\mathrm{N}$ & $\mathrm{C}_{4}-\mathrm{C}_{14}$ & $\mathrm{C}_{4}-\mathrm{C}_{15}$ & $\mathrm{C}_{4}-\mathrm{C}_{16}$ & $\mathrm{C}_{5}-\mathrm{C}_{15}$ & $\mathrm{C}_{5}-\mathrm{C}_{16}$ & $\mathrm{C}_{6}-\mathrm{C}_{15}$ \\
\hline weight & 4729 & 4003 & 5629 & 6219 & 7341 & 5218 \\
\hline $\mathrm{N}$ & $\mathrm{C}_{6}-\mathrm{C}_{17}$ & $\mathrm{C}_{7}-\mathrm{C}_{19}$ & $\mathrm{C}_{8}-\mathrm{C}_{12}$ & $\mathrm{C}_{8}-\mathrm{C}_{13}$ & $\mathrm{C}_{9}-\mathrm{C}_{10}$ & $\mathrm{C}_{9}-\mathrm{C}_{14}$ \\
\hline weight & 4210 & 3260 & 2510 & 2217 & 4836 & 2667 \\
\hline
\end{tabular}

- $\quad$ Time data.

In order to reach a certain range of customer service level, it is necessary to limit the up and down time of transportation, the lower limit time is limited to 0 matrix, the upper limit time limit is shown in table 5 .

TABLE II. CEILINGSCHEDULEBETWEEN SOME NODES(UNIT: HOUR)

\begin{tabular}{|c|c|c|c|c|c|c|c|c|c|c|}
\hline $\mathrm{N}$ & $\mathrm{C}_{10}$ & $\mathrm{C}_{11}$ & $\mathrm{C}_{12}$ & $\mathrm{C}_{13}$ & $\mathrm{C}_{14}$ & $\mathrm{C}_{15}$ & $\mathrm{C}_{16}$ & $\mathrm{C}_{17}$ & $\mathrm{C}_{18}$ & $\mathrm{C}_{19}$ \\
\hline $\mathrm{C} 1$ & 71 & 71 & 69 & 68 & 69 & 74 & 75 & 77 & 76 & 78 \\
\hline $\mathrm{C} 2$ & 66 & 68 & 72 & 75 & 70 & 71 & 74 & 79 & 73 & 84 \\
\hline $\mathrm{C} 3$ & 72 & 67 & 70 & 71 & 70 & 71 & 73 & 73 & 70 & 77 \\
\hline $\mathrm{C} 4$ & 71 & 68 & 69 & 70 & 69 & 70 & 71 & 76 & 72 & 76 \\
\hline $\mathrm{C} 5$ & 68 & 69 & 66 & 68 & 66 & 72 & 73 & 77 & 73 & 74 \\
\hline C6 & 70 & 66 & 67 & 69 & 68 & 69 & 70 & 71 & 69 & 75 \\
\hline C7 & 71 & 66 & 69 & 70 & 67 & 70 & 71 & 73 & 71 & 73 \\
\hline C8 & 66 & 63 & 64 & 66 & 64 & 65 & 67 & 67 & 66 & 71 \\
\hline C9 & 70 & 61 & 67 & 69 & 63 & 65 & 70 & 70 & 67 & 70 \\
\hline
\end{tabular}

- Other cost data.

When switching from one mode of transportation to another mode of transportation, it has the corresponding replacement cost. The unit cost shown in table 6 .

TABLE III. TRANSPORT MODE CONVERSION UNIT COST(UNIT: YUAN/TON)

\begin{tabular}{|c|c|c|c|}
\hline & highway & railway & waterway \\
\hline highway & 0 & 3.09 & 5.23 \\
\hline railway & 3.09 & 0 & 26.62 \\
\hline waterway & 5.23 & 26.62 & 0 \\
\hline
\end{tabular}

In addition, the transportation costs of roads, railways and waterways are 0.4 yuan/ton $\bullet \mathrm{km}, 0.3$ yuan/ton $\bullet \mathrm{km}$ and 0.15 yuan/ton, the speed is $76 \mathrm{~km} / \mathrm{h}, 84 \mathrm{~km} / \mathrm{h}$ and $57 \mathrm{~km} / \mathrm{h}$ respectively; the handling charge for the product is 3.87 yuan/ton; the unit load time is 0.04 hours.According to the characteristics of company at present, both the maximum time penalty factor and the lower limit time penalty factor are the minimum positive values.

\section{B. Model Solution Result}

After many times running MATLAB program, the optimal transportation path selection is carried out in $18 \mathrm{O}$-D cities, for example, the iterative convergence of C4 to C14 is shown in figure 6.

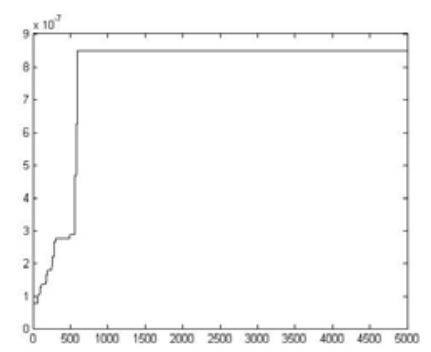

FIGURE VI.

ITERATIVE DIAGRAM OF MULTIMODAL TRANSPORT FROM C4 TO C14

By iterative operation, the minimum cost of the optimal path from C4 to C14 is 1178,500 yuan, the optimal individual is 4-15-14--3-1, which is mean that Starting from Shanghai, reached Shenzhen by water fist, and then reached Huizhou by road.

The minimum total cost of the optimal path through the iterative operation of 18 o-d pairs is 20097,000 yuan, and the output optimal individual and decoding are shown in table 7. 
TABLE IV. OPTIMAL INDIVIDUAL AND DECODING COMPARISON TABLE FOR MULTIMODAL TRANSPORT NETWORKS

\begin{tabular}{|c|c|c|c|}
\hline $\mathrm{N}$ & Decode & Individual & cost \\
\hline 1 & Nanjing $\stackrel{\text { steamship }}{\rightarrow}$ Shenzhen $\stackrel{\text { car }}{\rightarrow}$ Huizhou & $\begin{array}{c}1-15-14--3- \\
1\end{array}$ & 1265700 \\
\hline 2 & Nantong $\stackrel{\text { steamship }}{\rightarrow}$ Yangjiang & 2-18--3 & 732800 \\
\hline 3 & Suzhou $\stackrel{\text { car }}{\rightarrow}$ Shanghai $\stackrel{\text { steamship }}{\rightarrow}$ Shantou & $3-4-10--1-3$ & 491400 \\
\hline 4 & Suzhou $\stackrel{\text { car }}{\rightarrow}$ Shanghai $\stackrel{\text { steamship }}{\rightarrow}$ Shanwei & $3-4-11--1-3$ & 595800 \\
\hline 5 & $\begin{array}{c}\text { Suzhou } \stackrel{\text { car }}{\rightarrow} \text { Shanghai } \stackrel{\text { steamship }}{\rightarrow} \text { Gunagzhou } \\
\stackrel{\text { train }}{\rightarrow} \text { Shaoguan }\end{array}$ & $\begin{array}{c}3-4-16-12-- \\
1-3-2\end{array}$ & 1118800 \\
\hline 6 & 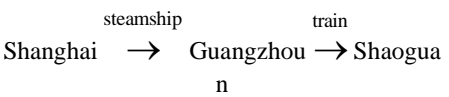 & $\begin{array}{l}4-16-12--3- \\
2\end{array}$ & 1350200 \\
\hline 7 & Shanghai $\stackrel{\text { steamship }}{\rightarrow} \underset{\mathrm{n}}{\text { Guangzhou }} \stackrel{\text { car }}{\rightarrow}$ Qingyua & $\begin{array}{l}4-16-13--3- \\
1\end{array}$ & 1432600 \\
\hline 8 & Shanghai $\stackrel{\text { steamship }}{\rightarrow}$ Shenzhen $\stackrel{\text { car }}{\rightarrow}$ Huizhou & $\begin{array}{l}4-15-14--3- \\
1\end{array}$ & 1178500 \\
\hline 9 & Shanghai $\stackrel{\text { steamship }}{\rightarrow}$ Shenzhen & 4-15--3 & 1396600 \\
\hline 10 & Hangzhou $\stackrel{\text { steamship }}{\rightarrow}$ Shenzhen & 5-15--3 & 1668900 \\
\hline 11 & Hangzhou $\stackrel{\text { steamship }}{\rightarrow}$ Guangzhou & 5-16--3 & 2065800 \\
\hline 12 & Jiaxing $\stackrel{\text { car }}{\rightarrow}$ Shanghai $\stackrel{\text { steamship }}{\rightarrow}$ Shenzhen & $6-4-15--1-3$ & 1546600 \\
\hline 13 & Jiaxing $\stackrel{\text { car }}{\rightarrow}$ Shanghai $\stackrel{\text { steamship }}{\rightarrow}$ Wuzhou & $6-4-17--1-3$ & 1529500 \\
\hline 14 & Ningbo $\stackrel{\text { steamship }}{\rightarrow}$ Maoming & 7-19--3 & 868900 \\
\hline 15 & Jinhua $\stackrel{\text { train }}{\rightarrow}$ Shaoguan & 8-12--2 & 902800 \\
\hline 16 & $\begin{array}{c}\text { Jinhua } \stackrel{\text { car }}{\rightarrow} \text { Wenzhou } \stackrel{\text { steamship }}{\rightarrow} \text { Guangzhou } \\
\stackrel{\text { car }}{\rightarrow} \text { Qingyuan }\end{array}$ & $\begin{array}{c}8-9-16-13-- \\
1-3-1\end{array}$ & 761600 \\
\hline 17 & Wenzhou $\stackrel{\text { steamship }}{\rightarrow}$ Shantou & 9-10--3 & 632500 \\
\hline 18 & Wenzhou $\stackrel{\text { steamship }}{\rightarrow}$ Shenzhen $\stackrel{\text { car }}{\rightarrow}$ Huizhou & $\begin{array}{l}9-15-14--3- \\
1\end{array}$ & 558400 \\
\hline $\mathrm{T}$ & - & - & 20097400 \\
\hline
\end{tabular}

\section{Analysis and Evaluation}

The previoustransportationmodeof the seaport logistics company in Zhejiang province is distributing motor vehicles by cargo traffic between two points, then the motorcade directly starts off from the point of departure to the destination, and this mode of transportation is a single mode of direct transports. The total cost of highway single mode of transportation that is using MATLAB to solve is 37,092,000 yuan.

Through the construction of multi-modal transport logistics network, Different o-d pairs need to choose the shortest path at the lowest cost. According to the solution results, the path of each o-d pair is shown in figure 7.

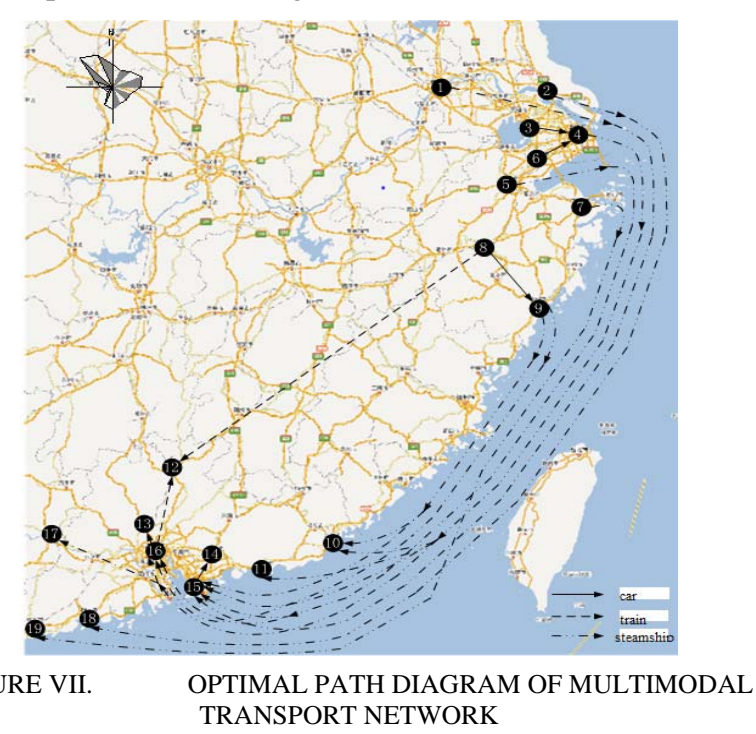

Figure 7 shows the optimal path graph, which has been transferred twice, is 3-12 and 8-13, the O-D pair arriving through one transit has $1-14,3-10,3-11,4-12,4-134-14,6-$ 156-17 and 9-14, the directly arrived O-D pairs are 2-18, 4-15, $3-15,5-16,7-19,8-12$, and $9-10$. In the 19 O-D pairs, there is no scale effect. Each line is an independent transport of goods, with a total cost of rmb20097,000.The improvement rate shows the reducedcost ratio which is basing on the original highway single mode of transportation cost as the benchmark, among them, the multi-modal transport network reduced the cost by $16994,000 y u a n$, and improved the ratio by $45.8 \%$, which reduced the cost by 16994,000yuan more less than the direct transportation network. The multimodal transport network has obvious advantages over the original direct transport.

\section{CONCLUSION}

Explorethe multimodal transport and genetic algorithm theories' integrated application in logistics system planningby reading a large number of literatures on two theories of multimodal transport and genetic algorithm.On the basis of comparative analysis of various modes of transportation, consider the cost of transportation, replacement cost and time penalty, and a multi - modal transport network model based on Improved Genetic Algorithms is established. Using improved genetic algorithm to solve the model not only can guarantee the diversity of population, avoid local optimal solution, but also enhance the algorithm searching ability. Simulating the model with MATLAB computing platform and the optimal network operation scheme is obtained. Taking the actual data of an enterprise as the case study object, the validity verification and empirical analysis of multimodal transport 
network model are carried out. The results show that the cost of multi-modal transport network operation mode is reduced by $45.8 \%$, thus the validity and practicability of the network operation model proposed in this paper are verified, which has certain guiding significance in the practice of enterprise case. However, this paper does not consider the changes and economic benefits brought about by the whole multimodal transport network after forming a hub center.

\section{REFERENCES}

[1] Yang Qinbo. Multi-modal transport overview in America[J]. Railway Freight Transport, 2005, 29(5): 39-41.

[2] Stephan Krygsman, Martin Dijst, Theo Arentze. Multimodal public transport: an analysis of travel time elements and the interconnectivity ratio [J]. Transport Policy, 2004, 98(11): 265-275.

[3] HediAyed, DjamelKhadraoui, ZinebHabbas. Transfer Graph Approach for Multimodal Transport Problems[J]. Communications in Computer and Information Science, 2008, 93(14):538-547.

[4] H Ayed, C Galvez-Fenandez. Solving time-dependent multimodal transport problems using a transfer graph model[J]. Combinatorial Optimizatiion in Industrial Engineering, 2011, 32(61):391-401.

[5] YM Bontekoning, C Macharis. Is a new applied transportation research field emerging?-a review of intermodal rail-truck freight transport[J]. Transportation Research Part A: Policy and Practice, 2004, 19(38): 1-34.

[6] Dennis Rondinelli, Michael Berryb. Multimodal Transportation, Logisties and the Environmenit Managing Inieraetions in a Global Eeonomy[J]. European Management Joumal,2000, 18(4):398-410.

[7] Angelica Lozano, Giovanni Storchi. Shortest viable path algorithm in multimodal network[J]. Transportation Research Part A: Policy and Practice, 2001, 17(35): 225-241.

[8] Bas Groothedde, CeesRuijgrok, Lo'riTavasszy. Towards collaborative intermodal hub networks-A case study in the fast moving consumer goods market[J]. Transportation Research Part E, 2005, 12(41):567-583.

[9] Yang Yuntao. Research on the legal relationship of international cargo multimodal transport.[D]. Beijing: University of International Business and Economics, 2006.

[10] Wei Hang, Li Jun. An Algorithm for Shortest Path with Multi -Modal in Time -Varying Network[J]. Chinese Journal of Management Science, 2006, 7(4): 56-63. 